\title{
Tras la pista de las CRUCES ROSADAS EN LA PARTE DE LOS CRÍMENES de LA NOVELA 2666 de Roberto Bolaño
}

\author{
Susan Peñuela-Rodríguez ${ }^{1}$ \\ Universidad del Valle, Colombia
}

\begin{abstract}
Resumen: El feminicidio de 119 mujeres y la secuencia de actos que se narran de los mismos son la trama principal de "La parte de los crímenes", capítulo del libro 2666 (2004) del escritor Roberto Bolaño. Entre desgarradores, aterradores y violentos sucesos descritos por medio de un narrador en tercera persona, "La parte de los crímenes" (2004) redescubre la trágica historia de los múltiples asesinatos de las maquiladoras de la Ciudad de Juárez, en su mayoría mujeres entre los 15 y 25 años de edad, las cuales fueron además violadas y torturadas. Tras el uso de la narración desgarradora y los detalles violentos del capítulo de los crímenes, se esconde el motivo de la literatura como acto de memoria a las mujeres que sufrieron en su cuerpo el horror del desplazamiento, la pobreza, la inequidad, la falta de oportunidades y la falta de reconocimiento social.
\end{abstract}

Palabras clave: Feminicidio; historia; memoria; Roberto Bolaño.

\section{On the trail of the pink crosses in the crime part of Roberto Bolaño's 2666 novel}

\begin{abstract}
The murder of 119 women and the sequence of events that are narrated by them are the plot of "The Part about the Crimes", a chapter from the novel, "2666" written by the author Robert Bolaño in 2004. Among the heartbreaking, frightening and violent events described by a narrator in third-person, "The part about the crimes" (2004) retells the tragic story of a multiple killing of female assembly plant workers in the city of Juárez. The women, who were between fifteen and twenty-five, were also raped and tortured. Behind the heartbreaking narrative and the violent details of the crimes, the underlying reason for the story is a memorial to these women who suffered the horror of displacement, poverty, inequality, a lack of opportunities and a lack of social recognition.
\end{abstract}

\footnotetext{
${ }^{1}$ Susan Peñuela Rodríguez es Licenciada en Lenguas Extranjeras de la Universidad del Valle y tesis meritoria de la Maestría en Literatura Colombiana y Latinoamericana de la Universidad del Valle. Correo electrónico: susan.penuela@javerianacali.edu.co
} 
Keywords: Killing; memorial; murder; Roberto Bolaño; story; women.

\section{La historia detrás de la narración}

Desde 1993 en la Ciudad de Juárez se han venido presentando asesinatos en contra de las mujeres provenientes del sector social más bajo de México, muchas de ellas de las poblaciones rurales con problemas de pobreza, falta de educación y desempleo. Debido a esta combinación de falta de oportunidades e inequidad social, estas mujeres, que por lo regular se encuentran entre los 15 y 25 años, deciden desplazarse a las ciudades en busca de trabajos como maquiladoras en una industria que se encuentra en auge desde el Tratado de Libre Comercio celebrado entre Estados Unidos y México en el año 1993.

A partir de este contexto histórico, Roberto Bolaño, escritor chileno y quien vivió en México en sus épocas de juventud, construye su narración en "La parte de los crímenes", uno de los cinco capítulos que contiene la novela póstuma 2666, publicada en 2004. En una combinación de usos del thriller, estilo de escritura propio norteamericano, y la descripción del cuerpo femenino como objeto de la violencia, Roberto Bolaño narra la historia turbulenta que se teje en una zona ficcional como lo es Santa Teresa, una ciudad que se encuentra en la frontera con Estados Unidos, con los múltiples feminicidios de víctimas jóvenes. Como se cita a continuación:

Esto ocurrió en 1993. En enero de 1993. A partir de esta muerta comenzaron a contarse los asesinatos de mujeres. Pero es probable que antes hubiera otras. La primera muerte se llamaba Esperanza Gómez Saldaña y tenía trece años. Pero es probable que no fuera la primera asesinada en el año 1993, ella encabezaba la lista. Aunque seguramente en 1992 murieron otras. Otras que quedaron fuera de la lista o que jamás nadie las encontró, enterradas en fosas comunes en el desierto o esparcidas sus cenizas en medio de la noche, cuando ni el que siembra sabe en donde, en qué lugar se encuentra (444).

De esta manera, Roberto Bolaño toma la fecha de 1993 como punto de partida para tejer los sucesos siniestros, es más, enfatiza en el mes en que ocurre el primer asesinato con el propósito de asentar la veracidad 
de los mismos. Es así como se construye desde un punto histórico "La parte de los crímenes", o como lo describe Baumgarten: "Toda novela, como producto de un acto de escritura, es siempre histórica, por lo tanto, reveladora de, por lo menos, un tiempo al que podríamos llamar tiempo de escritura o de la producción del texto" (68). Asimismo, la narración parte desde un punto histórico para rememorar a las mujeres que no cumplieron una función importante en la historia, por el contrario, fueron casi borradas de la misma.

\section{El cuerpo femenino como el objeto del crimen}

En la parte de los crímenes se describe la violencia ejercida sobre los cuerpos femeninos con tal detalle que no solo logra la impresión de lo que les ocurrió a estas mujeres, sino que además comunica, a través de estos cuerpos ultrajados, la acción del uso y desecho por el cual pasan las mujeres que ejercen el oficio de maquiladoras en el sector fronterizo de Santa Teresa. Como se describe a continuación por Bolaño:

Según esta, Esperanza Gómez Saldaña había muerto estrangulada. Presentaba hematomas en el mentón y en el ojo izquierdo. Fuertes hematomas en las piernas y en las costillas. Había sido violada vaginal y analmente, probablemente más de una vez, pues ambos conductos presentaban desgarros y escoriaciones por los que había sangrado profusamente. A las dos de la mañana el forense dio por terminada la autopsia y se marchó. Un enfermero negro, que hacía años había emigrado al norte desde Veracruz, cogió el cadáver y lo metió en un congelador (445).

El cuerpo de esta mujer presenta varios hematomas en el mentón, ojo izquierdo, piernas y costillas como sinónimo de lucha en contra de su agresor. Además, presenta penetración forzada anal y vaginal, provocando desgarros y escoriaciones. Acto seguido en la narración se hace una descripción con tintes criminalísticos intentando dar por terminada la autopsia metiendo el cuerpo de la mujer en un congelador y cerrando el caso. Es de esta manera que, utilizando el aparato judicial y el crimen organizado que enmarcan la zona, se logra poner en relieve otro tipo de organización que impera en la sociedad latina, y es el del uso y desecho del recurso humano, en este caso, de las mujeres que llevan sobre sus cuerpos la carga pesada de una sociedad que no las 
reconoce, que las marginaliza, que no les ofrece oportunidades y que por el contrario las castiga.

En este sentido, Foucault plantea que el castigo sobre los cuerpos es una fuerza que ejerce el Estado para controlar y ejercer poder sobre la población. A través de estos castigos se lograba comunicar el uso del poder como ejercicio legítimo de la ley por medio de métodos de tortura planificados, doblegando al criminal a través de un verdugo para lograr su confesión y por último su muerte. El aparato torturador, es decir el verdugo, marcaba el cuerpo con el propósito de dejar en claro que se estaba ejerciendo la justicia y se comunicaba este acto de salvajismo en una plaza pública para acaparar la atención de todo tipo de público. Como se ejemplifica a continuación:

Después de estos atenaceamientos, Damiens, que gritaba mucho, aunque sin maldecir, levantaba la cabeza y se miraba. El mismo atenaceador tomó con una cuchara de hierro del caldero mezcla hirviendo, la cual vertió en abundancia sobre cada llaga. A continuación, ataron con soguillas las cuerdas destinadas al tiro de los caballos, y después se amarraron aquéllas a cada miembro a lo largo de los muslos, piernas y brazos (7).

De esta manera se ejemplifica el uso del castigo corporal como mecanismo de control, y, por qué no, de materialización del cuerpo despojándolo de autonomía y convirtiéndolo en un objeto del suplicio. Es así como los primeros ejercicios del Estado lograron ejercer poder sobre la población marginada y controlaron las prácticas sociales hasta lograr prácticas modernas en las cuales se dejaron de hacer este tipo de actos públicos, desplazándolos a la clandestinidad de la esclavitud moderna y el crimen organizado.

\section{Tras las pistas de las cruces rosadas}

En 1996 en Lomas del Poleo, parte alta de Ciudad de Juárez, se encontraron 8 cuerpos de mujeres asesinadas con las mismas formas de tortura descritas en "La parte de los crímenes". Sus cuerpos fueron agredidos sexual y físicamente, por último las estrangularon y enterraron en la zona alta de la ciudad. Como forma de protesta y de honra a estas mujeres, se instalaron 8 cruces rosadas con el fin de no 
olvidar la forma violenta en que murieron. Aun así, desde los primeros crímenes registrados en 1993 hasta el 2012, se han reportados más de 7100 feminicidios, sin encontrar los culpables de tales delitos. En este sentido, aunque el homenaje a las víctimas se encuentra en un lugar visible de la ciudad, haciendo notoria esta problemática, los crímenes se siguen aún cometiendo.

Es en este punto donde el texto escrito logra recuperar esa parte no visible que estas víctimas femeninas no tuvieron, dotándolas de un relato en el cual se les da un nombre, una edad, unas descripciones físicas, se les da un rostro. Es aquí donde el acto de memoria resurge con el propósito de dar a las víctimas de la historia un presente que las honre. Como lo explica Quijano:

Esta nueva manera de relacionarse con el tiempo fue descrita por Andreas Huyssen como una "cultura de la memoria" debido al incremento, tanto en el espacio público como en el ámbito privado, de un interés caso obsesivo por la recuperación del pasado con el fin de paliar la ansiedad de un futuro que ha dejado de ser prometedor, para presentarse, algunas veces como incierto y, muchas más, como amenazante (38)

En este sentido la cultura de la memoria se generaliza y no solo queda representada en los monumentos convencionales, en las cruces rosadas por ejemplo, sino que además debido al descontento con la sociedad actual esta se recrea de otras formas, en este caso en una narración literaria. Es así como en la literatura posmoderna se generan dos maneras de cuestionar y representar el pasado, como ejemplifica Quijano:

Por un lado, una amplia producción de novelas históricas cuyo objetivo es debatir y criticar las historias oficiales que hasta mediados del siglo pasado habían ayudado a consolidar la memoria nacional...por otro lado, tenemos la aparición de narraciones literarias que trabajan con el pasado, ya no a partir de la organización de la historia nacional, sino más bien de la recuperación de historias particulares que reivindican memorias diseminadas, familiares, comunitarias y locales (39).

Es en esta última donde el sujeto se vuelve el eje central de la narración, y es sobre esta subjetividad de las vivencias y las experiencias 
del individuo que se recupera del pasado, como menciona Quijano: "Lo vivido por el sujeto, por su familia, por su grupo, por su comunidad" (39). Se reivindica (en este caso) la identidad propia que difiere de una identidad única cultural nacional. Esta última se encuentra por lo regular en las novelas históricas tradicionales, pero a diferencia de estas, existen también otro tipo de narraciones que tratan más sobre personajes particulares, como las múltiples mujeres que se describen en el apartado de los crímenes.

Esperanza Gómez Saldaña de 13 años, Luisa Celina Vásquez de 16 años, Guadalupe Rojas de 26 años, Gabriela Morón de 18 años, Leticia Contreras Zamudio de 23 años, Penélope Méndez Becerra de 11 años, América García Cifuentes de 23 años, Emilia Mena, Margarita López, la locutora Isabel Urrea, Isabel Cansino, más conocida como Elizabeth, quien se dedicaba a la prostitución, Elsa Luz Pintado, trabajadora del hipermercado del Norte y Andrea Pacheco Martínez de 13 años, quien fue raptada al salir de la escuela secundaria. Estas, entre muchas otras, conforman un colectivo de mujeres que fueron marcadas por un patrón en común: ser mujeres.

Cada una de estas es retratada en la narración con sus nombres y apellidos completos; solo en un par de ocasiones no se da una identidad a las víctimas. Aun así, la descripción de las mujeres es bastante precisa, su edad, ocupación, empresa donde trabajan y qué cargos ocupaban, también se logra describir de manera breve las características físicas de las mismas. Todo lo anterior con el propósito de dar un rostro a las víctimas de feminicidio de la ciudad de Santa Teresa. En algunas de las descripciones, con el fin de humanizarlas, se logra incluir la de los familiares, como es el caso de las niñas que fueron raptadas al salir del colegio. Como se demuestra continuación en el relato de Bolaño:

La siguiente muerta se llamaba Penélope Méndez Becerra. Tenía once años. Su madre trabajaba en la maquiladora Interzone-Beny. Su hermana mayor, dieciséis años, también prestaba sus servicios en la Interzone-Beny. El hermano que venía después, de quince, hacía de recadero y chico de los mandados de una panadería no muy lejos de la calle Industrial, donde vivían, en la colonia Veracruz. Ella era la menor y la única que estudiaba. Hacía siete años que el padre había abandonado el hogar (503) 
La recreación familiar permite generar una identidad de la víctima, en este caso desde las descripciones de sus padres y luego la de sus hermanos, todo lo anterior con el objetivo de crear una memoria subjetiva, una identidad que refleje la problemática que las mujeres enfrentan en esta zona peligrosa de México.

\section{Conclusiones}

Por todo lo anterior, "La parte de los crímenes" es el escrito conmemorativo de las mujeres que sufrieron en sus cuerpos las prácticas del uso y desecho de la capitalización moderna. Al ser en su mayoría inmigrantes de zonas rurales, necesitadas por trabajo y el sustento que este puede proveer, aceptaban las condiciones precarias y de explotación en el sector de las maquiladoras, el único dispuesto a recibirlas. En este se reflejan las condiciones de desigualdad, pobreza, falta de oportunidades y materialización de los cuerpos femeninos, convertidos solo en objeto de productividad en masa para una sociedad que las condena por su procedencia, la cual se sitúa en ese punto geográfico entre el límite de México y Estados Unidos, dos naciones que históricamente se han encontrado en disputa política, económica y social. Como ejemplo de lo anterior Sánchez y Melgoza mencionan que:

En el caso de Ciudad Juárez, las décadas recientes han sido el escenario en el cual se ha podido observar la emergencia y paulatina consolidación de un conjunto de prejuicios y estereotipos por parte de los originarios de la entidad hacia los migrantes. De manera particular, la sedimentación de una serie de estigmas tuvo como foco de atención inicial del segmento de mujeres jóvenes trabajadoras de las maquiladoras (Balderas, 2002). Empero, estos prejuicios hacia los migrantes, con contenidos regionalistas, clasistas y sexistas, se refirieron a la totalidad de los "fuereños", de ambos sexos y de cualquier grupo de edad. De esta manera, poco a poco se fueron generalizando expresiones como las siguientes: las obreras de la maquila eran las "maquilocas" (100).

Esta degradación de la población asalariada hacia las trabajadoras migrantes hace que se generen dinámicas de falta de reconocimiento del individuo como persona que hace parte de una comunidad, que piensa, 
que siente, que trabaja por un motivo interno, que "se la juegan por Juárez" (100) ya que en sus lugares de origen no tuvieron oportunidades que les permitieran generar un recurso mínimo para la manutención de sus hogares. A todo lo anterior Sánchez y Melgoza agregan que:

Este proceso de formación de estereotipos no solamente identifica al objeto: también lo califica, lo ubica en un orden de valoración y, con ello, lo sujeta al juicio de los demás. Así, las obreras de las maquiladoras eran pensadas en el imaginario de la ciudad como las mujeres "fáciles", como las "plumitas", y el conjunto de los migrantes eran vistos como "los otros", como los que llegaban a "quitarle el trabajo a los de Juárez". En estas circunstancias, Ciudad Juárez perdió buena parte de su carácter como lugar abierto y generoso para los forasteros, y con el paso del tiempo devino un lugar realmente hostil hacia "los otros", orientación que encontramos efectivamente en muchos lugares en los cuales ocurre con cierta intensidad este "encuentro" entre originarios y migrantes (100).

Es esta hostilidad la que genera heridas profundas en especial en la comunidad femenina, haciéndola vulnerable ante todo tipo de actos violentos y convirtiéndolas en objetos de suplicio y mecánicas sociales que manipulan tanto sus cuerpos como sus derechos. Lo que anteriormente se consideraba un lugar de posibilidades para los "otros" se convirtió en un foco de violaciones y asesinatos que no parece parar aun en los años recientes.

Ante esta constante violencia y vulneración de los Derechos Humanos en los parques industriales de la Ciudad de Juárez, se generó como medio de protesta un movimiento sindicalista con el propósito de exigir garantías mínimas a su precaria situación laboral, como se ejemplifica a continuación: "En adc, 200 obreros y obreras demandan aumento salarial y denuncian malos tratos, vejaciones, hostigamiento laboral y sexual y despidos injustificados" (108). Además de lo anterior, las problemáticas se visibilizaron en el momento en que las trabajadoras migrantes deciden protestar en pro de mejorar sus condiciones laborales y de vida, como se expone a continuación por Sánchez y Melgoza: 
Ante la cercanía de los meses más fríos del año, instalaron tiendas de campaña provistas de "calentones", de "discos" (de acero) para cocinar y asar carne, así como catres y colchonetas para pernoctar, donde se podía ver a las obreras con sus hijos pequeños durante las "guardias", muchas de ellas "madres solteras", como pudimos constatar en nuestra visita a uno de estos plantones a finales de octubre de 201510 (109).

Gracias a todo esto, es posible evidenciar cómo, en el transcurso de los años, la minimización hacia las migrantes (por su procedencia y situación económica) ha generado un impacto social en la Ciudad de Juárez, el cual cambia y evoluciona de acuerdo a la época y las problemáticas que se presenten en esta. Pasando desde la explotación laboral, hasta la deshumanización de las mujeres migrantes, la violencia que sufrieron a causa de su lugar de procedencia es solo la justificación para una sociedad que no las reconoce como iguales, sino como otros, como seres inferiores incluso para las clases más bajas. Tras una lucha por sus derechos que duró años, es así como las mujeres mencionadas en "La parte de los crímenes", que en su mayoría pertenecen a zonas apartadas de México, logran un mínimo reconocimiento dentro del ámbito literario y también un pequeño monumento que las conmemore: Las cruces rosadas.

\section{Referencias}

Baumgarten, Carlos. "Aproximaciones a la nueva novela histórica brasileña". Revista anual de estudios literarios. 12 (2008): 67-79. Digital.

Bolaño, Roberto. $2666 \mathrm{La}$ parte de los crímenes. Barcelona: Editorial Anagrama, 2004. Impreso.

Foucault, Michel. Vigilar y Castigar: Nacimiento de la prisión. Argentina: Siglo XXI Editores, 2002. 17 Jun. 2019. Digital.

Quijano Velasco, Mónica. "Geografías del recuerdo: Memoria, literatura y exilio". Andamios. 8 (2011): 37-61. Digital.

Sánchez Díaz, Sergio G. y Javier Melgoza Valdivia. "Reestructuración en las maquiladoras de Ciudad de Juárez y respuesta obrera". El Cotidiano 200 (2016, nov-dic): 99-109. Digital. 